\title{
De la elite civil a la elite política. Reproducción del poder en contextos de democratización
}

\author{
Gonzalo Delamaza \\ Gonzalo Delamaza Escobar, Universidad de Los Lagos. \\ Email: gonzalo.delamaza@ulagos.cl
}

\begin{abstract}
Resumen: Este artículo analiza las trayectorias de las personas que formaron parte de la elite política chilena entre 1990 y 2010 y que provenían de la sociedad civil organizada. Para ello se utilizan los datos de una encuesta de trayectoria aplicada a 386 personas que ocuparon cargos superiores en el ejecutivo, parlamento y partidos políticos durante el período. Se analiza la proveniencia, los canales de acceso, ubicación institucional de las personas provenientes de la sociedad civil y, eventualmente, su trayectoria de salida de posiciones formales de poder político durante el período. Se postula que las restricciones institucionales y el diseño de «elitismo democrático reforzado» de la transición chilena significaron que el amplio estamento de la sociedad civil chilena que accedió al poder político, pertenecía previamente a posiciones privilegiadas dentro de la misma, principalmente al segmento de mayor educación. También reforzó el peso y consolidación de una elite tecnopolítica, especialmente en el poder ejecutivo.
\end{abstract} ción.

Palabras clave: elite política, sociedad civil, tecnopolítica, democratiza-

\section{From civil elite to political elite. Reproduction of power in contexts of democratization}

\begin{abstract}
This article analyzes the trajectories of people who were part of the chilean political elite between 1990 and 2010 and who came from civil society organizations. For that it uses data from a trajectory survey of 386 people who occupied top positions in the executive, parliament and political parties during the period. We analyze the origin, access channels and institutional placement of persons from civil society and, eventually, their way out of formal positions of political power. We hypothesize that the institutional constraints and the design of «reinforced democratic elitism» of the chilean transition meant that the wide segment of civil society that came to political power, previously belonged to privileged positions within it, mainly to the more educated segment. It also reinforced the importance and consolidation of a «techno-political elite», mainly in the executive branch.
\end{abstract}

Key words: political elite, civil society, technopolitics, democratization.

\section{Desde a elite civil à elite política. A reprodução do poder em contextos de democratização}

Resumo: Este artigo analisa as trajetórias das pessoas provenientes da 
sociedade civil organizada que faziam parte da elite política do Chile entre 1990 e 2010. São usados dados de uma pesquisa aplicada a 386 pessoas que ocupavam altos cargos no executivo, o parlamento e os partidos políticos durante o período. Ele analisa a origem, os canais de acesso e localização institucional de pessoas da sociedade civil e, eventualmente, o seu caminho fora das posições formais de poder político durante o período. Nossa hipótese é que as limitações institucionais eo desenho do «elitismo democrático fortalecido» da transição chilena fez com que a ampla camada da sociedade civil chilena chegou ao poder político anteriormente pertencia a posições privilegiadas dentro dela, principalmente o segmento de maior educação. Ele também reforçou o peso ea consolidação de uma «elite tecno-política», especialmente no Poder Executivo .

Palavras-chave: elite política, sociedade civil, tecnopolitica, democratização.

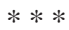

Este trabajo amplía la discusión sobre modos específicos mediante los cuales se forman y reproducen las elites políticas en contextos de democratización. Tomando a Chile como caso de estudio, se postula que esta formación y reproducción se asocia principalmente a dos condiciones del proceso político, que definen en gran medida su relación con la sociedad: las condiciones institucionales en que se ejerce el poder y la concepción de democracia que predomina. Nuestra hipótesis es que la transición pactada con la dictadura saliente y el predominio de la concepción de elitismo democrático crearon las condiciones para el tránsito de los integrantes de la sociedad civil al Estado, restringiéndolo principalmente a su segmento de mayor educación y perfil tecno-político. El segmento de la elite que analizamos es aquél que proviene de la sociedad civil organizada y que transita hacia posiciones de poder político entre los años 1990 (inicio del período democrático) y 2010 (fin del período político de la coalición de centroizquierda la Concertación- en el poder ejecutivo).

\section{La política democrática y las elites políticas}

El elitismo democrático (Avritzer 2002; Nun 2002) es una característica general del proceso político que establece las oportunidades y restricciones para el acceso a las posiciones de poder. La comprensión de la democracia exclusivamente como un conjunto de mecanismos pluralistas y competitivos para la selección de elites no sólo restringe las oportunidades de participación y privilegia el rol de las estructuras institucionalizadas para dicha selección, los partidos políticos. También, de acuerdo a Avritzer (2002) en sociedades excluyentes y desiguales, reduce las capacidades integradoras que ha tenido en otros contextos, como el europeo de la post guerra.

En determinadas condiciones institucionales y políticas el elitismo conduce a la expansión de la tecnopolítica, entendida como incremento de la invocación de legitimidad técnica para el liderazgo, que se traduce en el aumento de la proporción de personas con mayor dotación de capital edu- 
cacional en las posiciones de poder político (Centeno y Silva 1998). Este fenómeno debilita la capacidad representativa de la política, pues reduce el círculo de los que pueden acceder al poder institucionalizado a quienes han disfrutado previamente de las oportunidades para acumular educación y capital cultural en general. Pero también reduce el alcance de la dimensión representativa de la política, al retirar asuntos importantes de la esfera de la deliberación pública, confiándolo a especialistas, legitimados por el conocimiento dominante o por sus propios pares.

La continuidad en el tiempo de las restricciones políticas de la democracia pactada y de la concepción elitista, favorecen la generación de vasos comunicantes entre las elites políticas y la alta conducción empresarial, dado el rol disminuido del Estado en materias económicas y su papel como promotor del crecimiento económico en manos privadas. Finalmente, también favorece el vínculo entre las elites políticas y un segmento altamente calificado y profesionalizado de la sociedad civil organizada, que comparte orígenes sociales y capital cultural, aún cuando puedan tener posiciones políticas encontradas en determinados momentos. Como consecuencia es esperable un efecto conservador, que dificulta tanto la circulación como la renovación de las elites políticas.

En términos weberianos, nos estamos refiriendo así a políticos profesionales, vale decir, individuos que viven por y para la política transformando dicha actividad en una vocación. Este fenómeno se relaciona con la expansión de la esfera pública en el siglo XX, la modernización de los Estados y a las olas democratizadoras, como es el caso chileno (Alcántara 2012; Best y Cotta 2000; Marenco y Serna 2007). El fenómeno de la profesionalización de la política se entremezcla con los estudios sobre élites, los cuales se han enfocado en el rol que juegan éstas en los procesos de transición democrática (Higley y Burton 1989; Higley y Gunther 1992) y en las características de las élites nacionales, además de su nivel de cohesión y consenso (Best 2011; Pakulski 2012).

El estudio del reclutamiento político ha sido un instrumento utilizado para abordar el desarrollo de las élites y el fenómeno de la profesionalización de la política. El reclutamiento político se ha estudiado en base a dos perspectivas de acuerdo a Serna (2006): (a) con foco en los procesos al interior del sistema político, particularmente en las estructuras de oportunidades que ofrece el sistema electoral y las formas institucionales de reclutamiento y selección de los partidos, muy en la línea del trabajo de Norris (1997); y (b) con foco en el estudio de la especialización de agentes políticos desde una perspectiva más sociológica, muy ligada a la sociología política francesa, particularmente a los trabajos de Bourdieu (1997, 2013) y Offerlé (2004).

Norris (1997) ofrece un modelo de reclutamiento donde lo describe como un proceso influido por el sistema legal, electoral y el sistema de partidos, asimismo el reclutamiento se ve sometido a las necesidades y características con respecto al suministro de aspirantes (eventuales políticos 
profesionales o miembros de la élite) y a las expectativas de los seleccionadores (partidos políticos o grupos de notables). Por otra parte, Siavelis y Morgenstern (2008) explican el rol del reclutamiento y la selección de casos en el poder ejecutivo y legislativo en seis casos de América Latina (Argentina, Brasil, Chile, Colombia, México y Uruguay). De acuerdo a Piñeiro (2009) la obra de Siavelis y Morgenstern (2008) tiene dos puntos fuertes: (a) la combinación de variables institucionales con variables ligadas al funcionamiento de los partidos; y (b) colocar el proceso de selección como variable dependiente. Por último, Best y Cotta (2000) evidencian el rol que las élites parlamentarias juegan en el proceso de interacción entre sociedad y política, constituyéndose como una proyección de la sociedad en el campo político y al mismo tiempo como elementos politizadores de la sociedad mediante una interpretación de los flujos societales. En este sentido, el proceso de reclutamiento se ve mediado por las características individuales de los actores, los seleccionadores y sus características, la imagen del actor ante a la opinión pública (electorado), y la estructura formal de oportunidades (e.g., leyes, prácticas del campo político, lógicas institucionales, etc.).

El reclutamiento político está vinculado a las trayectorias de los individuos, las cuales son condicionadas por la especialización de los agentes y sus estructuras de capitales específicas. Los patrones típicos de las trayectorias en puestos políticos de acuerdo a Marenco (2006) son: (a) carreras basadas en reputación personalizada derivada del origen familiar, fortuna, diplomas de prestigio, por la actividad profesional (e.g., ingreso tardío y colateral a la política desde profesiones que están estrechamente ligadas al ámbito público); y (b) carreras basadas en recursos electorales adquiridos en posiciones políticas y partidarias. El reclutamiento social de acuerdo a Dogan (1999) puede ser por: (a) osmosis debido a la ocupación de una posición elevada en el espacio social; (b) predisposición dada por desempeño profesional de carreras afines (e.g., economistas, abogados, cientistas sociales, entre otros); y (c) absorción de la sociedad civil, lo cual se da especialmente en el caso de dirigentes sindicales y estudiantiles. El último caso podría considerarse desde la perspectiva de la sociología política como una reconversión de capitales que permite pasar del campo social al campo político (González Bustamante 2013).

Por último en la literatura científica sobre elites políticas es posible distinguir por una parte el enfoque unitario que enfatiza la cohesión de la elite políticamente dominante- del enfoque pluralista, en el que se identifican diferentes componentes de la misma (Joignant 2011). El mismo autor establece tres ámbitos principales de desarrollo de los estudios recientes sobre elites políticas: los estudios empíricos sobre elites gubernamentales; el creciente rol y peso de los economistas y el estudio de los technopols (Ibíd.) En el caso chileno las tres variantes tienen escaso desarrollo. El primer ámbito ha sido principalmente abordado por historiadores (Correa 2004; Gazmuri 2001), mientras que los dos restantes han sido objeto del trabajo de sociólogos (Valdés 1995; Montecinos 1998; Silva 1991 y 2011). En el presente artículo se amplía el análisis al ámbito de la sociedad civil 
organizada y sus vínculos con el poder político, utilizando la trayectoria de personas que pasaron de un ámbito al otro.

Luego de la breve discusión conceptual en torno a elites y reclutamiento político, en la segunda parte se conceptualiza los rasgos de la transición democrática que fundamentan las hipótesis del trabajo respecto de la importancia de las restricciones institucionales de la transición y el predominio del elitismo democrático. Llamaremos a esta convergencia elitismo democrático reforzado. En la tercera sección se abordan las particularidades históricas de la sociedad civil chilena. Luego se caracteriza el perfil de los individuos pertenecientes a la elite política según su participación previa en organizaciones de la sociedad civil. En la cuarta sección se analizan algunos subgrupos dentro de los encuestados, comparándolos entre sí en relación a su trayectoria: movimientos estudiantiles, colegios profesionales, organismos no gubernamentales (ONG), centros de estudio y organismos de derechos humanos. También se comparan rasgos de la elite parlamentaria estableciendo semejanzas y diferencias entre los bloques político de derecha y centro-izquierda. La quinta sección aborda las conclusiones del trabajo e identifica temas de investigación que surgen de él.

\section{Condiciones de la Transición Democrática y Elitismo Político}

Como se sabe, la transición chilena definió la arena política a partir de la negociación entre las fuerzas de apoyo de la dictadura de Pinochet y la amplia coalición que lo había derrotado en el plebiscito de 1988. Durante los dieciocho meses que Pinochet permaneció aún en el gobierno con posterioridad a la derrota, se negociaron algunas reformas a la Constitución Política de 1980, postponiéndose sin embargo, los cambios más sustantivos que demandaba la oposición. Al mismo tiempo el gobierno se ocupó de culminar el proceso de privatizaciones económicas y en completar sin negociación alguna- la dictación de gran parte de las Leyes Orgánicas Constitucionales que le permitían prolongar su régimen, pues requieren mayorías calificadas para su modificación. Durante ese mismo período, y con los resultados del plebiscito sucesorio a la vista, el régimen militar rediseñó los distritos electorales y estableció la ley respectiva, con el fin de fortalecer la presencia parlamentaria de sus fuerzas de apoyo (Huneeus 2000; Otano 1995).

En marzo de 1990 se renovó el ejecutivo y asumió la primera legislatura, sólo parcialmente electa, puesto que la presencia de senadores designados se prolongó hasta 2006. Ingresó de esta forma al Estado una gran cantidad de personas, respaldadas por un proceso de legitimación democrático. Gran parte de ellos provenían de las organizaciones de la sociedad civil y habían estado involucrados en la lucha democrática (en el caso de la Concertación) o en el respaldo a la dictadura (en el caso de la coalición de derecha, la Alianza por Chile). A pesar de la larga prohibición de la activi- 
dad política, la inmensa mayoría de los incorporados al Estado pertenecían también a partidos políticos.

La estabilidad política de los siguientes veinte años permitió la conformación progresiva de una poderosa élite, ya que los mismos partidos permanecieron en el gobierno y en el parlamento: cuatro que restan de la Concertación (inicialmente eran 17 partidos y movimientos) y dos de la derecha. ${ }^{1}$ En 2006 asume la primera legislatura completamente electa y en 2010 ingresan por primera vez al parlamento tres diputados del Partido Comunista, gracias a un pacto con la Concertación y algunos independientes fuera de pacto. ${ }^{2}$

La asunción de la presidenta Michelle Bachelet (2006-2010) representó un intento por renovar la composición de la élite en el poder ejecutivo desde 1990, a través de medidas como la equidad de género en la composición del gabinete y los puestos superiores de la administración y el intento por evitar nombrar a los mismos altos funcionarios de los gobiernos anteriores. Ambas medidas tuvieron una implementación parcial por la fuerte resistencia de los partidos políticos y la élite en general, como se evidencia en la mayor inestabilidad y cambios de gabinete (Silva 2011).

Las condiciones específicas de la transición tuvieron consecuencias sobre el perfil de la elite y sobre los partidos políticos, particularmente en un país de tradición presidencialista y escasas facultades parlamentarias. Se tendió a conformar una élite tecnocrática de gran autonomía y los partidos perdieron algunas de sus funciones tradicionales. En el caso del oficialismo, estos tendieron a estatizarse convirtiéndose en una suerte de brokers de su electorado ante el ejecutivo, quien conduce la agenda política, apoyado por las directivas superiores de los partidos. Estas seleccionan a los candidatos a representantes populares con plantillas nacionales que aseguren el equilibrio de las coaliciones. Vale decir los partidos mantienen cierta efectividad en la función de reclutamiento de personal, conservan el alineamiento básico de 1988 y formalmente gobiernan, aunque en la práctica han ido perdiendo legitimidad y respaldo. A su vez el sistema político en su conjunto es el que disminuye su efectividad en la construcción de lo público como lo muestran las encuestas políticas más importantes. ${ }^{3}$

El sistema electoral binominal se eligen dos representantes por cada distrito electoral, uno del bloque mayoritario y otro del minoritario- ha impedido la ampliación y pluralización del sistema político representativo, blindando a los partidos políticos, siempre que estos se mantengan al interior de las coaliciones mayoritarias, que consiguen prácticamente todos los sillones parlamentarios. A partir de 2007 se comenzó a producir públicamente una mayor disidencia de parlamentarios al interior de los partidos, dando origen al fenómeno de los díscolos, especialmente dentro de la Concertación. En algunos casos ello ha terminado en escisiones. ${ }^{4}$

En el plano de la teoría política, la posición que predominó durante la transición se sustentaba en una visión de la democracia en la que se 
reserva a las élites el papel clave en la conducción del proceso político y a la población en general el papel de optar entre unas y otras al momento de las elecciones, oponiéndose a toda forma de populismo o expresión directa de los intereses de los grupos subordinados (Avritzer 2002; Martucelli y Svampa 1993). En los supuestos originales del elitismo democrático (Schumpeter 1946) estaba el carácter pro democrático de las élites políticas y su autonomía respecto de las fuerzas económicas y sus intereses particulares (Nun 2002). Esos supuestos evidentemente no se verificaban en Chile hacia fines de la dictadura y sólo se han ido desarrollando con posterioridad paulatina y parcialmente.

En el caso chileno, la concepción elitista se profundizó con la opción por sobrerepresentar a la derecha, adaptando algunos planteamientos de la democracia consociativa, que había sido propuesta por los teóricos de la gobernabilidad para escenarios de alta polarización (Liphart 1999). La adaptación chilena del concepto fue en sentido contrario de la intencionalidad de los teóricos originales del mismo, que buscaban asegurar la representación de minorías y grupos cuyos intereses no quedaban adecuadamente representados por la regla de mayoría. En Chile, en cambio, se consideró que la participación ciudadana constituiría, en sociedades fragmentadas, heterogéneas o sobreideologizadas, una incertidumbre o amenaza desestabilizadora de la democracia. Lo que se aceptó en negociación, entonces, fue sobrerepresentar a la primera minoría, que expresaba a los principales dueños del poder económico, social y cultural, por sobre la regla de la mayoría en el sistema político, con el fin de darle estabilidad (Ruiz 1993). Ello no fue sólo una astucia de la estrategia de transición, sino que responde a razones más de fondo: se hizo para evitar que en ella se produjera el pluralismo polarizado del que hablaba Arturo Valenzuela, entendido como desborde de la participación que en el diagnóstico de la elitehabría dado origen y causado en última instancia el golpe militar del 1973 (Valenzuela 1978). ${ }^{5}$

Las consideraciones anteriores reforzaron la presencia e influencia política de un estamento técnicamente especializado dentro de la política, los llamados technopols (Domínguez, 1997) o, más ampliamente elites tecnopolíticas (Cortés 2000). Por cierto la tecnocratización de la gestión política, particularmente en la rama ejecutiva, no es exclusiva del caso chileno, pero en este caso se verificó un conjunto amplio de factores a favor del surgimiento y consolidación de lo que podemos llamar tecnócratas democráticos, parafraseando el concepto de democracias tecnocráticas (Centeno y Silva 1998: 11).

La influencia de los tecnopoliticos se ejerce principalmente a través de puestos de relevancia en el ejecutivo y en los instrumentos clave para el diseño de políticas públicas: generación de conocimiento especializado, comunicación pública, lobby político y presencia en organismos internacionales. Entre esos factores puede mencionarse el fuerte presidencialismo, que disminuye el peso del Congreso como instancia política representativa. También es relevante la cohabitación forzada y acep- 
tada con las políticas neoliberales vigentes en diversos aspectos de la institucionalidad, ideología con mucho peso en los medios de comunicación, los think tanks y también en las políticas de organismos internacionales. También la estrategia exitosa de contención de demandas sociales durante la transición, que quitó presión social y política a la burocracia.

En síntesis, en Chile se conjugaron factores específicos del proceso político restricciones que surgieron de la negociación pactada con los representantes del régimen militar- con una concepción democrática elitista. Ambas produjeron una combinación de gran estabilidad entre el predominio político de una coalición mayoritaria controlando el ejecutivo y una oposición con poder de veto en el congreso y proyectaron en el tiempo el peso de la tecnocracia (dentro y fuera de la Concertación). El peso de la tecnopolítica había sido importante con los Chicago Boys, que rediseñaron la economía chilena durante el régimen militar y siguió siéndolo con los que Patricio Silva denominó como los monjes de CIEPLAN, así como posteriormente con los hombres de Expansiva que han conducido gran parte de la gestión económica, política y social durante la democracia (Silva 2011). ${ }^{6}$ En cualquier caso, tal como lo planteó el mismo Silva al inicio de la transición, los tecnócratas chilenos continúan trabajando dentro de los partidos políticos (Silva 1991: 407). Al mismo tiempo, esos partidos ya no cumplen la función ni tienen la relevancia que tuvieron en el pasado, ni condicionan significativamente la acción de esos tecnócratas. ${ }^{7}$

En las condiciones de la transición chilena se reforzaron mutuamente las características elitistas del proceso y las restricciones de la política representativa, con el desarrollo del circuito extrainstitucional del poder. Ello dio lugar a lo que puede sintetizarse como elitismo democrático reforzado, que ha caracterizado a nuestro juicio a la democracia chilena con posterioridad a 1990. Ello significa que los rasgos del proceso operan en el mismo sentido restrictivo y, como argumentaremos, condicionan también el acceso al poder político de quienes provenían de la sociedad civil.

\section{La sociedad civil y sus contextos específicos}

Cada sociedad es particular en su conformación y en las pautas de su desarrollo. La sociedad civil chilena se ha conformado de acuerdo a ciertas características propias de la evolución histórica del país. Se requiere, entonces, comprender esas particularidades que la configuran y evaluar el impacto de la path dependence que ello puede significar.

En primer término conviene destacar el predominio histórico del Estado sobre la sociedad, resumido por el historiador chileno Mario Góngora (1981) en la radical expresión según la cual el Estado es la matriz de la nacionalidad, la Nación no existiría sin el Estado. Un Estado marcado, además, por la guerra: contra los mapuches, contra España, contra los países vecinos y entre facciones políticas en guerras civiles durante el siglo XIX (Delamaza 2010). 
Durante parte del el siglo XX se vivió el predominio del sistema político y los partidos como los mediadores fundamentales de los intereses sociales, articulados parcialmente en grandes movimientos nacionales, aunque con importantes exclusiones. Si bien no predominó en la política y la sociedad civil chilena el clientelismo propiamente tal que se dio más en los niveles localespuede decirse que la sociedad civil perdió autonomía y se fue haciendo crecientemente corporativa, asociada a los proyectos estatales. La sociedad civil tuvo tradición de autonomía en el siglo XIX, pero luego se articuló al proyecto estatal bajo la mediación política de los partidos (Salazar y Pinto 1999).

El golpe militar de 1973 y la larga dictadura que le sucedió (hasta 1990), desarticularon tanto a la sociedad civil como a los partidos. La primera comenzó a reorganizarse en pequeños espacios a partir de los grupos de defensa de los derechos humanos y la protección de la Iglesia Católica. Desde 1983 se masificó el descontento con el gobierno militar y se vivieron dos períodos de intensa movilización social y política: el de las protestas nacionales (1983 - 1986) y el del plebiscito (1988). Eso dio una gran visibilidad a diversas y nuevas formas de participación de la sociedad civil, tras la cual estaban también los debilitados partidos políticos. Sin embargo el diseño de la transición política como se señaló- desmovilizó a los grupos sociales y condujo el proceso a través de un acuerdo limitado a las modificaciones en la institucionalidad representativa, sin cambio constitucional de por medio (Delamaza 2010).

La sociedad civil no constituye una totalidad homogénea, antes bien, está atravesada por las un sinnúmero de diferencias, más aún en sociedades tan desiguales como la chilena. Pero más allá de esa característica general, interesa distinguir los tipos de organización de pertenencia, puesto que ellos también son muy diversos. En relación al tema que nos interesa -el vínculo con la política- la pauta organizacional tradicional de la sociedad civil chilena estaba compuesta por las organizaciones reivindicativas de los segmentos sociales vinculados al Estado de compromiso, vale decir sindicatos, agrupaciones empresariales y gremios de las clases medias, como colegios profesionales (Garretón 1985).

En cada uno de los sectores sociales involucrados, el paso a lo político se ejerció tradicionalmente según un modelo de vinculación con el Estado algo diferente. En el caso de los empresarios, a partir de la ruptura política producida con el liderazgo de Arturo Alessandri en los años veinte del siglo pasado, esta no se produjo a través de los partidos políticos, puesto que sólo alcanzaron el gobierno durante un período en 1958, con su hijo, Jorge Alessandri (1958-1964). Antes bien, la principal estrategia empresarial consistió en intentar controlar o ejercer influencia desde dentro, en instituciones claves del arreglo socioeconómico en un modelo con fuerte presencia del Estado en el desarrollo (Correa 2004; Moulian 2006; Valdivia 2010). Las clases medias, en cambio, crecieron y se hicieron influyentes tanto a través de organizaciones políticas como el Partido Radical (PR) y la Democracia Cristiana (DC), como a través del acceso directo a la burocracia estatal y su continua expansión hasta 1973. El movimiento sindical, por 
su parte, actuó muy ligado a la representación política, negociando con los partidos obreros el Partido Comunista (PC) y el Partido Socialista (PS)- a partir de organizaciones nacionales que presionaban por obtener reivindicaciones específicas (Collier y Collier 2001)

A lo anterior se debe agregar un segmento de especial relevancia para la reproducción del liderazgo político como son las federaciones estudiantiles, desde la creación de la Federación de Estudiantes de Chile (FECH) en la Universidad de Chile en los años veinte, hasta la actualidad. Algo similar puede decirse de los Colegios Profesionales, que sin tener un rol político tan visible y directo, fueron de gran importancia para los liderazgos de clase media profesional y su ingreso al Estado.

Sin embargo, y tal como lo conceptualizan Collier y Handlin (2010) esa pauta organizacional varió significativamente con las transformaciones sociales y del Estado en América Latina. Nuevas formas de agrupación se desarrollaron, entre las cuales destacan las organizaciones no gubernamentales (ONG), las organizaciones ciudadanas territoriales y las surgidas a partir de identidades culturales. Se trata de redes asociativas, compuestas por organismos mucho más dispersos y diversos, donde la relación con los partidos políticos no cumple un rol central, puesto que es más distante, intermitente e instrumental (2010:5).

En el contexto chileno de desarticulación social y política producida por el régimen militar, adquirieron preeminencia también otro tipo de organizaciones. Desde allí saldrían también un número importante de líderes políticos. Como se verá, el componente más relevante de este conjunto, a partir del cual se realizó el reclutamiento político durante la transición fueron los centros de estudio y las organizaciones denominadas actualmente think tanks, las cuales están centradas en la producción de conocimiento aplicado y buscan influir directamente en las políticas públicas (Brunner y Barrios 1987; Lladser 1990; Gárate 2008)

\section{Consideraciones metodológicas y operacionales sobre la elite política}

¿A quiénes considerar válidamente como miembros de la elite política? En términos conceptuales que puedan hacerse operativos, normalmente se considera tanto el ocupar posiciones formales de poder, como el ejercicio de ese poder en decisiones políticas (Berkowitz 1982; Putnam 1976). Otro grupo es el de quienes no ocupan posiciones formales pero ejercen poder o influencia política, que se aborda con los enfoques llamados reputacionales. Ambos son complementarios en cuanto a lo que abarcan y también lo que no incluyen. Mientras el primero tiene mejor representación estructural de las elites, el enfoque reputacional registra eventualmente mejor la dinámica de poder tal cual esta es percibida por los diferentes actores. En este trabajo se utiliza el primero de los enfoques, 
abarcando un período político completo y como tal bastante extenso (veinte años). También se aborda un universo completo de la elite política chilena: el personal superior del ejecutivo de la totalidad de los ministerios y otras reparticiones públicas; parlamentarios que han sido reelectos durante el período y, finalmente, se incluye a los dirigentes de partidos políticos con representación parlamentaria que han durado más de un período en su cargo. ${ }^{8}$ De esta manera se está incluyendo a las diferentes fuerzas políticas y alcanzando una visión amplia de la elite política chilena para el período 1990 - 2010.

La metodología empleada fue la aplicación de encuestas presenciales acerca de la trayectoria personal y política a la totalidad de las personas que cumplían los criterios de pertenencia a la elite político institucional en el país durante el período. Del total de 565 individuos identificados de este modo, se logró encuestar a 386 de ellos, lo cual representa el 68\% de los integrantes del universo definido que estaban vivos al momento de la encuesta (2011). ${ }^{9}$ La ventaja de utilizar un período relativamente extenso de tiempo es que permite controlar algunos de los problemas metodológicos usuales a los estudios que se basan en posiciones institucionales formales: su vinculación efectiva a las decisiones políticas y lo contingente de las posiciones. El criterio utilizado en este caso permite incluir en la elite sólo a aquellos que ocuparon las posiciones más altas del ejecutivo y a quienes fueron capaces de permanecer ocupando cargos en diversos momentos (a través de la reelección o de una segunda designación), lo que se considera como un indicador de poder efectivo. Adicionalmente, un problema usual es que aparte de las dificultades para reconocer los miembros de la élite, la principal complicación operativa es que sus miembros no están disponibles para ser estudiados (Espinoza 2010: 262). La alta tasa de respuesta obtenida permite en este caso superar este problema.

En la Tabla $\mathrm{N}^{\circ} 1$ se clasifica los entrevistados según su posición institucional más relevante. ${ }^{10}$

\section{Tabla $\mathrm{N}^{\circ} 1$}

\section{Elite Política Chilena 19902010 según posición institucional}

\begin{tabular}{|l|c|c|}
\hline Cargo & N & $\%$ \\
\hline Presidente & 3 & 0,8 \\
\hline Ministro & 105 & 27,2 \\
\hline Subsecretario & 41 & 10,6 \\
\hline Senador & 25 & 6,5 \\
\hline Diputado & 120 & 31,1 \\
\hline Senador & 25 & 6,5 \\
\hline Diputado & 120 & 31,1 \\
\hline Jefe de división y/o gabinete & 64 & 16,6 \\
\hline $\begin{array}{l}\text { Director Banco Central, Superintendente, } \\
\text { Director empresas públicas }\end{array}$ & 17 & 4,4 \\
\hline Total & $\mathbf{3 8 6}$ & $\mathbf{1 0 0}$ \\
\hline & 77 & \\
& & \\
\hline
\end{tabular}

Fuente: Encuesta Elite Política 2011 


\section{Trayectorias individuales: de la sociedad civil organizada a la elite política}

La primera dimensión empírica que interesa analizar es hasta que punto la elite política que comenzó a configurarse en 1990 proviene efectivamente de la sociedad civil organizada o, por el contrario se constituye principalmente a partir de cuadros políticos preexistentes, sin participación en la misma. Probablemente por la larga duración del régimen militar, la renovación de la elite se profundizó: por una parte ingresaron al parlamento los provenientes del régimen saliente y, por otro, muchos que se habían vinculado a organizaciones pro democráticas, ingresaron tanto al parlamento como al ejecutivo.

El conjunto de la elite política encuestada, aplastantemente masculina en su composición, manifiesta un predominio absoluto de personas que declaran haber participado en diverso tipo de organizaciones sociales antes de asumir sus cargos. Los que no participaron superan apenas el 11\% del total, como se aprecia en la Tabla $\mathrm{N}^{\circ} 2$.

Tabla $\mathrm{N}^{\circ} 2$

Integrantes de la elite según pertenencia a organizaciones

\begin{tabular}{|c|c|c|c|c|c|c|}
\hline \multirow{2}{*}{ Personas } & \multicolumn{2}{|c|}{ Perteneció } & \multicolumn{2}{c|}{ No perteneció } & \multicolumn{2}{c|}{ Total } \\
\cline { 2 - 7 } & $\mathbf{N}$ & $\%$ & N & $\%$ & N & $\%$ \\
\hline Hombre & 289 & 74,9 & 33 & 8,6 & 322 & 83,5 \\
\hline Mujer & 53 & 13,7 & 11 & 2,8 & 64 & 16,5 \\
\hline Total & 242 & 88,6 & 44 & 11,4 & 386 & 100 \\
\hline
\end{tabular}

Fuente: Encuesta Elite Política 2011

Esto podría llevar a concluir apresuradamente que la elite política proviene al amplio espectro de la ciudadanía organizada y no de la militancia política. Ello, sin embargo, debe ser desechado desde el inicio, puesto que, de acuerdo a la misma encuesta, el 93,5\% de los encuestados milita en un partido político. Vale decir que no hay aquí una superposición entre ambas pertenencias, consistente con la tradición chilena de alta vinculación entre sociedad y política. ${ }^{11}$ Se debe agregar ahora el perfil específico de la pertenencia organizacional previa de la elite política, que se presenta en la Tabla $\mathrm{N}^{\circ} 3$. 


\section{Tabla $\mathbf{N}^{\circ} 3$ \\ Pertenencia organizacional según tipo de organización}

\begin{tabular}{|c|c|c|}
\hline Organización & $\%$ & $\mathbf{N}$ \\
\hline Organizaciones estudiantiles & 44,3 & 171 \\
\hline Colegios profesionales & 41,5 & 160 \\
\hline Centros de estudios & 31,1 & 120 \\
\hline $\begin{array}{l}\text { Asociaciones y movimientos religiosos, } \\
\text { filosóficos o espirituales }\end{array}$ & 23,3 & 90 \\
\hline ONG & 22,0 & 85 \\
\hline Org. territoriales, vecinales o funcionales & 18,4 & 71 \\
\hline Asociaciones de Derechos Humanos & 17,4 & 67 \\
\hline Clubes de membresía de pago & 15,3 & 59 \\
\hline Organizaciones de voluntariado & 13,2 & 51 \\
\hline Asociaciones gremiales o empresariales & 8,8 & 34 \\
\hline Asociaciones y movimientos culturales & 7,3 & 28 \\
\hline Organizaciones sindicales & 4,9 & 19 \\
\hline Otra & 4,4 & 17 \\
\hline $\begin{array}{l}\text { Asociaciones étnicas o comunidades } \\
\text { indigenas }\end{array}$ & 0,3 & 1 \\
\hline
\end{tabular}

Fuente: Encuesta Elite Política 2011

El perfil asociativo de la elite chilena muestra varios rasgos de transformación respecto del pasado democrático anterior a 1973, que evidencian las diferencias del nuevo arreglo político post noventa, así como también algunos de continuidad. En primer lugar el elitismo social que revela. Así, las tres primeras categorías de pertenencia federaciones estudiantiles, colegios profesionales y centros de estudio- están indicando la prevalencia de las clases medias ilustradas en la composición de la elite. Las dos primeras categorías corresponden a los lugares tradicionales de reproducción del segmento profesional de las elites políticas en el ámbito social y muestran indirectamente la importancia que estos espacios organizacionales tuvieron durante la lucha democrática contra Pinochet. Dedicaremos a ellas un apartado especial para analizarlas.

En cambio otras organizaciones de igual o mayor importancia en el accionar político de los años ochenta y cantera tradicional de reproducción del liderazgo, como lo son las organizaciones sindicales, obtienen una participación marginal en la composición de la elite política. En el caso del ejecutivo su presencia es nula y en el parlamento se trata de un fenómeno acotado a la DC y a los tres principales líderes del período de las protestas nacionales. ${ }^{12}$

Por otra parte, las asociaciones que concentran la pertenencia so- 
brepasan muy ampliamente en importancia a aquellas organizaciones más propias de una elite oligárquica, como serían los clubes de membresía de pago y las asociaciones empresariales. Tal como lo indica la tabla precedente, estas ocupan un lugar muy subordinado en las menciones de la elite política. El reclutamiento político y la permanencia en la elite muestran un perfil mucho más ligado a la clase media profesional que a las posiciones de poder económico. ${ }^{13}$

En segundo lugar de importancia cuantitativa en cuanto a pertenencia organizacional, aparecen, sin embargo, organizaciones no tradicionales de reproducción del liderazgo, como son los centros de estudio, las ONG, las organizaciones territoriales y funcionales y los movimientos de derechos humanos. Por la importancia que reviste esta renovación y cambio de la relación entre sociedad y política, dedicamos a estas organizaciones un análisis específico. ${ }^{14}$

\section{La reproducción tradicional del liderazgo político de las clases medias profesionales en las organizaciones de la sociedad civil}

Las organizaciones y los líderes estudiantiles tuvieron un especial protagonismo en el derrocamiento del general Carlos Ibáñez en 1931, así como en las movilizaciones políticas de los años sesenta y setenta. Lo volverían a tener en las protestas en contra de Pinochet en los ochenta y en las movilizaciones masivas de 2006 y 2011. En cada coyuntura crítica se fueron creando organizaciones políticas con una fuerte presencia de los jóvenes universitarios. Así ocurrió con el surgimiento del PS en 1933, la Falange Nacional (que dio origen a la DC) en 1934, el Movimiento de Izquierda Revolucionaria (MIR) en la Universidad de Concepción en 1965, el Movimiento de Acción Popular Unitaria (MAPU) y el Movimiento Gremial, ambos en la Universidad Católica a fines de los años sesenta. Bajo la dictadura, la Federación de Estudiantes de la Universidad Católica, controlada por los gremialistas, también fue cantera de cuadros gubernamentales, que luego formaron la Unión Democrática Independiente (UDI) en 1987. De tal manera que las federaciones de estudiantes han sido una de las organizaciones de la sociedad civil donde más frecuentemente se formado el liderazgo político nacional, incluso creando nuevos partidos y movimientos políticos a partir de ello. Como se puede observar no se trata sólo de control político por parte de los partidos existentes, sino también renovación y cambio del sistema político a partir de la experiencia social y política de una generación de dirigentes y estudiantes. ${ }^{15}$

Los Colegios Profesionales, por su parte, siguieron una pauta más ligada a la protección corporativa del empleo y las profesiones, a través de una institucionalidad directamente vinculada al Estado. Así, ocurrió por ejemplo, con el Colegio de Abogados, que fue creado, financiado y estructurado como una repartición pública incorporada al presupuesto nacional y 
con funciones de tutela sobre la profesión, precisamente por su carácter público (Ibáñez 2003: 300 y ss.).

En la composición actual de la elite, vemos que nuevamente los movimientos estudiantiles y los colegios profesionales ocupan las posiciones principales: en ambos casos sobre un cuarenta por ciento de los encuestados menciona haber pertenecido a alguna de esas organizaciones. En el caso de las organizaciones estudiantiles, predominan sin contrapeso las organizaciones de estudiantes universitarios en todas sus expresiones, que cubren el 85\% de quienes participaron del movimiento estudiantil. No se trata de la pertenencia simple a la organización sino al ejercicio de roles dirigenciales, puesto que sobre el $80 \%$ de los encuestados fueron dirigentes en sus respectivas organizaciones. Como era esperable, el 95\% de ellos no siguió participando una vez asumidos los cargos políticos.

En cuanto a los Colegios Profesionales, se perciben tendencias muy concentradas en tres colegios de profesiones liberales de alto prestigio y organizaciones muy consolidadas en el país: abogados, ingenieros y médicos. El caso de los abogados alcanza al 45\% de las menciones, siguiendo la tendencia tradicional de fuerte presencia de esa profesión entre los políticos en Chile.

\section{Tabla $\mathbf{N}^{\circ} 4$ \\ Pertenencia a Colegios Profesionales}

\begin{tabular}{|l|c|c|}
\hline \multicolumn{1}{|c|}{ Colegios y Asociaciones } & N & $\%$ \\
\hline Colegio de Abogados & 72 & 45,0 \\
\hline Colegio de Ingenieros & 30 & 18,8 \\
\hline Colegio Médico & 21 & 13,1 \\
\hline Colegio de Profesores & 7 & 4,3 \\
\hline Colegio de Arquitectos & 7 & 4,3 \\
\hline Colegio de Sociólogos & 4 & 2,5 \\
\hline Asociación Chilena de Ciencia Política & 4 & 2,5 \\
\hline No especifica & 3 & 1,9 \\
\hline Otros colegios & 12 & 7,7 \\
\hline
\end{tabular}

Fuente: Encuesta Elite Política 2011

A diferencia del caso de las organizaciones estudiantiles, el 70\% de los participantes en estos colegios no cumplió en ellos labor directiva. Por ello puede verse esta participación como mera actividad gremial o, simplemente como una actividad más de estos líderes políticos, pero que no significó su proyección en un rol dirigencial. ${ }^{16}$ Ello se reafirma con el hecho que 
sólo el 45\% de quienes respondieron indica haber seguido participando luego de ocupar el cargo político, en circunstancias que no existe mayor incompatibilidad entre ambas participaciones (salvo el tiempo disponible).

En cuanto a asociaciones de reproducción tradicional del liderazgo, en adición a las mencionadas organizaciones de estudiantes y colegios profesionales, sólo se mantiene la presencia relevante de los movimientos religiosos. Hemos destacado la proveniencia católica de gran parte de la elite y la influencia de la Iglesia Católica en los líderes sociales y políticos. Esa influencia se intensificó con el rol que esta jugó como espacio de protección para el liderazgo opositor durante el período dictatorial, pero no se limita a él. También desde la derecha se desarrollan los movimientos apostólicos como el Opus Dei y los Legionarios de Cristo, que apuntan precisamente a captar a los líderes y la elite tanto económica como política del país. ${ }^{17}$

En este trabajo nos interesa destacar la permanencia de la Iglesia Católica y sus diferentes expresiones en la composición y desarrollo de la elite política. Examinando la composición interna de este grupo tenemos que la Iglesia Católica concentra el 76,6\% de las menciones, correspondiendo un 14,4\% a comunidades cristianas (principalmente las Comunidades de Vida Cristiana, CVX, de los jesuitas) y un 13,3\% a movimientos apostólicos como el Opus Dei, los Legionarios de Cristo y Schönstatt. El único otro grupo importante es la masonería, que agrupa a un 15,6\% de los noventa miembros de la elite que reportan participación en movimientos religiosos o filosóficos. En cambio los grupos cristianos no católicos alcanzan apenas a dos casos, no correspondiendo en absoluto al peso de los evangélicos de diversas denominaciones en la sociedad chilena.

\section{La reproducción no tradicional de la elite de clase media profesional: refugio político e impacto del conocimiento experto}

\section{De los centros académicos independientes a los think tanks}

Resulta especialmente relevante el caso de los Centros de Estudio, por su magnitud en menciones y porque se trata de organizaciones especializadas de conocimiento con fines de influencia social y política. Los primeros de ellos nacieron durante los años sesenta, como respaldo del proyecto de revolución en libertad del gobierno de Eduardo Frei Montalva (1964 - 1970). Con fuerte respaldo de la Iglesia Católica y la cooperación internacional, principalmente norteamericana, se crearon diversas instancias de estudio por fuera de las universidades, muy vinculadas con el proyecto político de la época. ${ }^{18} \mathrm{La}$ DC mantuvo centros de pensamiento vinculados a ella durante el régimen militar, pero también se crearon nuevos centros, el principal de ellos fue CIEPLAN del cual salieron las principales autoridades económicas de los gobiernos de la Concertación. CIEPLAN, 
así como el Programa Interdisciplinario de Investigaciones en Educación (PIIE) surgieron originalmente al alero de la Universidad Católica (UC) en el período de la reforma universitaria. Con la intervención de la universidad emigraron y se constituyeron como centros independientes. Otros centros de la UC fueron clausurados y varios de sus académicos se trasladaron a la Facultad Latinoamericana de Ciencias Sociales (FLACSO). Igual cosa ocurrió con académicos de sociología de las Universidades Católica y de Chile (Brunner y Barrios 1987; Lladser 1990; Puryear 1994). ${ }^{19}$

Por su parte la Iglesia Católica de Santiago, en 1975, durante el período del Cardenal Silva Henríquez, auspició la creación de Círculos de Estudio, para acoger a los académicos expulsados de las universidades, dando luego origen a la Academia de Humanismo Cristiano (AHC), posteriormente constituida como una universidad privada. La AHC mantuvo un promedio de 142 investigadores asociados a ella entre 1981 y 1987, llegando a publicar 144 libros en el mismo período (Lladser 1990: 224 - 225). El respaldo financiero para estos y otros centros provino de la cooperación internacional. ${ }^{20}$ María Teresa Lladser (1990: 255) contabiliza 117 libros publicados entre 1980 y 1985 por 21 centros de estudio catastrados.

Hacia fines de los años ochenta, en el marco de la relativa apertura política y la preparación de la transición política, se crearon diversos institutos de estudio y fundaciones asociadas a corrientes políticas específicas, siguiendo inicialmente el modelo europeo, para luego constituir los llamados think tanks. Estos últimos comparten con las fundaciones su orientación ideológica de base, pero tienen un perfil más definido en cuanto al seguimiento de políticas y la generación de conocimiento aplicado. Surge así la Fundación Chile 21, fundada por Ricardo Lagos, con profesionales vinculados al Partido por la Democracia (PPD) y el PS y la Fundación Jaime Guzmán, creada por la UDI. A inicios de los años noventa, el ex ministro de Hacienda de Pinochet y ex candidato presidencial de la derecha, Hernán Büchi, funda el Instituto Libertad y Desarrollo, para defender el neoliberalismo en las políticas públicas. Luego Renovación Nacional (RN) crea su propio Instituto Libertad y el PS el Instituto Igualdad, ocupando así el campo de debate en torno a las políticas públicas y realizando capacitación ideológica a sus militantes y simpatizantes. ${ }^{21}$

Ya señalamos la importancia de estas instituciones para la conformación del liderazgo político, como se evidencia en las 120 menciones $(31,1 \%)$ de las mismas entre los encuestados. Algunos de estos centros muestran claro impacto en la composición de la elite política y su reproducción, indicando que la proveniencia de los cuadros de la elite se concentra en unos pocos núcleos académico-políticos, como se indica en la siguiente tabla. Ocho centros principales concitan el $49 \%$ de las menciones. El restante $51 \%$ se reparte entre 45 centros diferentes. 
Tabla $\mathbf{N}^{\circ} 5$

Miembros de la Elite pertenecientes a Principales Centros de Estudio

\begin{tabular}{|l|c|c|}
\hline \multicolumn{1}{|c|}{ Centro de Estudio } & \multicolumn{1}{|c|}{$\begin{array}{c}\text { Personas } \\
\text { pertenecientes al } \\
\text { centro }\end{array}$} & Porcentaje \\
\hline Centro de Estudios del Desarrollo(DC) & 12 & $10 \%$ \\
\hline $\begin{array}{l}\text { Corporación de Investigaciones Económicas para América } \\
\text { Latina (principalmente DC) }\end{array}$ & 10 & $8 \%$ \\
\hline Instituto Chileno de Estudios Humanísticos (DC) & 8 & $7 \%$ \\
\hline Corporación de Promoción Universitaria(DC) & 7 & $6 \%$ \\
\hline Fundación Chile XXI(PPD, PS) & 7 & $6 \%$ \\
\hline Expansiva(liberales Concertación) & 5 & $4 \%$ \\
\hline CIDE(Compañia de Jesús) & 5 & $4 \%$ \\
\hline VECTOR(PS) & 5 & $4 \%$ \\
\hline Total centros principales (8) & $\mathbf{5 9}$ & $\mathbf{4 9 \%}$ \\
\hline Otros centros (45) & $\mathbf{6 1}$ & $\mathbf{5 1 \%}$ \\
\hline TOTAL & $\mathbf{1 2 0}$ & $\mathbf{1 0 0} \%$ \\
\hline
\end{tabular}

Fuente: Encuesta Elite Política 2011

\section{Las ONG y su trayectoria}

Los antecedentes de lo que hoy llamamos ONG se encuentran de modo más directo en un cierto segmento de la sociedad civil organizada que no son las organizaciones sociales representativas o corporativas. Se trata más bien de otro tipo de instituciones, mayoritariamente surgidas de la Iglesia Católica o vinculadas a ella de diferentes formas. Dichas instituciones desarrollaron innumerables actividades de intervención social y educativa desde muy temprano en la historia del país.

La trayectoria histórica de este tipo de organizaciones también aparece vinculada a la Iglesia Católica y su tradicional acción de voluntariado. Sin embargo es en los años sesenta, durante el gobierno de Frei Montalva, cuando se establecen muchas de las que permanecen hasta hoy y acordes con el modelo profesionalizado de acción social que las caracteriza. Las dos grandes expansiones de la acción social y política de la época fueron la reforma agraria y la llamada promoción popular, es decir el intento por organizar formalmente a los pobladores y pobladoras urbanos, para otorgarles modos de participación en el ámbito vecinal. De la primera nació el sindicalismo campesino y de la segunda, las juntas de vecinos y los centros de madres, las llamadas organizaciones territoriales y funcionales. El vehículo de promoción de dichas reformas fueron algunos organismos del Estado. Pero también se apoyó sobre instituciones no gubernamentales que formularon muchas de las propuestas y realizaron acciones de capacitación y formación de líderes, promovieron iniciativas de educación popular. Todos ellos vinculados a acciones de la iglesia que acompañaban el proceso social y político.

El contexto creado por la dictadura militar, al cerrar los espacios de participación y aplicar una política económica de fuerte impacto negativo sobre las condiciones de vida de los sectores populares, produjo como re- 
acción el surgimiento de nuevas organizaciones y la reconversión de algunas antiguas. Sucesivas oleadas de organismos que combinaron la atención a problemas sociales y de derechos humanos vulnerados con acciones de organización, educación, concientización y agitación política y social.

La mayor cantidad y variedad de ONG surgió durante la década de los ochenta, sustentadas por la cooperación no gubernamental y la solidaridad obtenida por el exilio chileno para las acciones dentro del país. Los espacios no gubernamentales fueron decisivos para la rearticulación de la iniciativa social y política en diferentes segmentos de la sociedad chilena. Detrás de la emergencia del movimiento de ONG estaba la evolución de una estrecha alianza e intercambio de propósitos, estrategias y metodologías de trabajo entre una cooperación internacional políticamente democrática e influenciada por las corrientes del exilio latinoamericano, una generación de profesionales y técnicos con experiencia de militancia social y política o participación en el gobierno a partir de mediados de los años sesenta y, por último, líderes sociales, comunitarios y militantes políticos de base que participaron en la reconstrucción de los vínculos y valores del movimiento social popular.

La presencia de las ONG como pertenencia previa de los miembros de la elite política es menor que la de los centros de estudio, pero aún así resulta muy significativa (22,5\%) superando tanto a las organizaciones territoriales como al sindicalismo. Si se considera a las asociaciones de derechos humanos como parte de este fenómeno, el total agregado resulta aún mayor. La pauta de distribución de las menciones, sin embargo, es mucho más dispersa y variada que en el caso de los centros de estudio. Sólo una ONG concentra cinco menciones. Se trata del Programa de Economía del Trabajo (PET). El PIIE y el Centro de Asesoría Sindical (CIASI) reciben tres menciones cada una. ${ }^{22}$ Ello refuerza el privilegio de este tipo de centros y del conocimiento que producen, en la selección de las elites políticas. Aparte de las instituciones mencionadas, otras seis ONG reciben dos menciones cada una, mientras las demás se distribuyen entre 58 organizaciones. A su vez el $62 \%$ de los encuestados ocupó roles dirigenciales en ellas, lo que parece estar indicando que más que un vínculo fuerte de las ONG como tales a la política, lo que se verificó fue la selección de individuos específicos, dirigentes de las mismas y militantes de partidos políticos, para integrar las filas del Estado. Consecuentemente con ello, sólo un 22\% de los participantes en ONG lo siguió haciendo luego de haber asumido sus cargos políticos.

\section{Los movimientos y asociaciones de defensa de los derechos humanos}

El otro segmento nuevo en el panorama de la sociedad civil chilena son las asociaciones de derechos humanos. Corresponden a un perfil parcialmente diferente a los anteriores, particularmente aquellas que agrupan a los familiares de las víctimas de la represión política, asemejándose a organizaciones de membresía. Un segundo grupo son las asociaciones crea- 
das para la defensa y promoción de los derechos humanos como causa política y moral en el contexto de la dictadura. Finalmente se encuentran los organismos profesionales dedicados a estas labores, principalmente nacidos de la Iglesia Católica. De hecho también se utiliza el término ONG de derechos humanos. De tal manera que la clasificación ofrecida tiene más que nada un valor heurístico y es posible realizar otras.

El perfil prevaleciente de pertenencia de los miembros de la elite es bastante claro en relación a las asociaciones de derechos humanos. La Comisión Chilena de Derechos Humanos fue el espacio más importante de reunión y vínculo de quienes hoy forman parte de la elite, recibiendo 18 menciones (27\% del total). Le siguen Amnistía Internacional (8) y la Comisión Pro Derechos Juveniles (CODEJU) (7). El organismo especializado creado por la Iglesia Católica, la Vicaría de la Solidaridad (y el Comité Pro Paz que la antecedió) fueron lugar de pertenencia de ocho de los encuestados. Por otra parte, cinco encuestados reportan haber pertenecido a alguna de las agrupaciones que reunieron a los directamente afectados por la represión política en sus diversas formas. El 55\% de las personas vinculadas a estos movimientos y asociaciones ocupó posiciones directivas y sólo un 19\% siguió participando en ellas una vez asumido los cargos políticos.

\section{Articulación del sector no gubernamental con la política}

El tránsito de un segmento de los participantes de las organizaciones no gubernamentales a la política y a formar parte de la elite en los veinte años siguientes, se entiende a partir de los datos expuestos y la cercanía existente entre la acción política (principalmente en el bloque pro democrático) y la del sector no gubernamental. Sin embargo ese tránsito fue más extendido entre los centros de estudio, captando de este modo al segmento de mayor educación y mayor especialización relativa. Así, los centros de estudio prácticamente duplican a las asociaciones y movimientos de derechos humanos en cuanto a pertenencia de los grupos de elite. El reclutamiento entre los centros de estudio resulta más amplio y extendido, mientras en el caso de las ONG y los movimientos de derechos humanos, es menor y en las primeras limitado a personas individuales que ocupaban en ellos cargos directivos.

Por último, la prevalencia y predominio de los centros de estudio como cantera de la elite política se puede considerar como un fenómeno duradero y con proyección de futuro, mientras el caso de las ONG y los movimientos de derechos humanos correspondió a un período determinado de la política chilena. No sólo aparece ya un think tank de reciente creación como Expansiva entre los más mencionados, sino que se han seguido creando otros centros de gran influencia. También en la composición del gabinete y los equipos de conducción política y técnica del gobierno de derecha de Sebastián Piñera (2010 - 2014) se advierte una significativa presencia de integrantes de los think tanks y fundaciones de ese sector. 


\section{Segmentos de la elite política y su pertenencia a organizaciones de la sociedad civil}

Un último análisis abarca a las diferentes ramas o segmentos de la elite considerada, en relación a las principales fuentes de pertenencia organizacional previa. Como puede observarse en la Tabla $\mathrm{N}^{\circ}$ 6, la composición interna de la elite difiere bastante en su adscripción previa, lo cual debiera dar lugar a hipótesis sobre trayectorias políticas más detalladas y precisas. En primer término destaca que la participación en el movimiento estudiantil resulta mayoritaria sólo para los parlamentarios. Pero también resalta el hecho que el personal ejecutivo que hemos llamado de conducción técnica también proviene significativamente del movimiento estudiantil. Ello puede deberse a un cierto perfil más político de dichos cargos (antes que meramente técnico) o bien al hecho de que probablemente en todos los casos se trata de profesionales universitarios lo que, junto a las redes políticas creadas en la actividad estudiantil les otorgan mayores posibilidades de acceso y permanencia en los cargos. En ambos casos se trata de una proveniencia mucho más significativa que la existente en relación a los Centros de Estudio y las ONG.

En el caso de los cargos superiores de conducción política del ejecutivo, la preeminencia la tienen los Centros de Estudio para los presidentes y ministros, reafirmando la hipótesis tecnopolítica de este trabajo. Mientras que para los subsecretarios e intendentes de alta permanencia, nuevamente es el movimiento estudiantil el que prevalece. En todos los casos las ONG son el sector de menor importancia en cuanto a proveniencia. Sin embargo en los cargos de conducción política es menor la distancia con respecto a las demás categorías. Así lo indica la Tabla $\mathrm{N}^{\circ} 6$.

Tabla $\mathbf{N}^{\circ} 6$

Principales organizaciones de proveniencia por segmentos de la elite (\%)

\begin{tabular}{|c|c|c|c|c|c|c|c|}
\hline Segmento & $\begin{array}{c}\text { Org. } \\
\text { Estudian } \\
\text { tiles }\end{array}$ & $\begin{array}{c}\text { Colegios } \\
\text { Profesio } \\
\text { nales }\end{array}$ & $\begin{array}{c}\text { Centros } \\
\text { de } \\
\text { Estudio }\end{array}$ & $\begin{array}{c}\text { Asoc. } \mathbf{y} \\
\text { Movs. } \\
\text { Religioso } \\
\text { s }\end{array}$ & ONG & $\begin{array}{c}\text { Orgs. } \\
\text { Territori } \\
\text { ales y } \\
\text { Funcion } \\
\text { ales }\end{array}$ & $\begin{array}{c}\text { Orgs, de } \\
\text { Derechos } \\
\text { Humano } \\
\text { s }\end{array}$ \\
\hline $\begin{array}{c}\text { Presidentes y } \\
\text { Ministros }\end{array}$ & 39 & 46 & 48 & 22 & 26 & 9 & 20 \\
\hline Senadores & 71 & 39 & 25 & 25 & 18 & 21 & 32 \\
\hline Diputados & 46 & 41 & 21 & 26 & 17 & 32 & 18 \\
\hline $\begin{array}{l}\text { Subsecretarios e } \\
\text { Intendentes }\end{array}$ & 39 & 51 & 34 & 15 & 29 & 12 & 12 \\
\hline $\begin{array}{c}\text { Ejecutivos de } \\
\text { entidades semi- } \\
\text { autónomas }\end{array}$ & 30 & 41 & 41 & 36 & 18 & 0 & 0 \\
\hline $\begin{array}{l}\text { Jefes de División } \\
\text { y Gabinete }\end{array}$ & 39 & 23 & 19 & 18 & 21 & 16 & 12 \\
\hline $\begin{array}{c}\text { Directivos de } \\
\text { Partidos Politicos }\end{array}$ & 30 & 83 & 17 & 67 & 17 & 33 & 17 \\
\hline PROMEDIO & 44 & 41 & 31 & 24 & 22 & 18 & 17 \\
\hline
\end{tabular}

Fuente: Encuesta de Elites Políticas 2011 
Si bien, como sabemos, la pertenencia organizacional previa es alta para el conjunto de la elite y ella se concentra en las organizaciones estudiantiles, colegios profesionales y centros de estudio, la tabla anterior nos permite distinguir pautas diferenciales según los segmentos de la elite. Es así como la mayor pertenencia organizacional previa se verifica entre los directivos de partidos políticos (lo cual puede estar distorsionado por su escaso número de acuerdo a la forma como se definió esa categoría). El extremo opuesto lo ocupa el segmento de apoyo al ejecutivo, esto es, los jefes de división y gabinete, que muestran la menor tasa promedio de pertenencia organizacional previa (21\%) considerando las siete categorías de organización principales.

Tal como habíamos hipotetizado, el perfil más tecnocrático, asociado a los think tanks es más acusado en el ejecutivo que en el parlamento y los partidos, donde está por debajo del promedio general. Sin embargo, dentro del ejecutivo, debemos excluir al segmento de apoyo, es decir los jefes de gabinete y división, cuya participación en los centros de estudio llega apenas al 18\%. Es necesario estudiar otros rasgos de ese grupo para profundizar en este aspecto. Si corresponde a un perfil más técnico, este no surge ni se asocia a los llamados think tanks; si corresponde a un perfil más político, este no se reprodujo tanto en la sociedad civil sino, probablemente, al interior de los propios partidos. Por el contrario, las tasas promedio más altas de pertenencia se presentan entre los directivos de partidos políticos y los senadores.

En todo el estamento superior del ejecutivo, vale decir los presidentes y ministros, así como los subsecretarios e intendentes, predomina la pauta general: colegios profesionales, centros de estudio y organizaciones estudiantiles. Entre los congresistas la participación más alta fue en organizaciones estudiantiles y colegios profesionales. Entre los diputados destaca sin embargo las organizaciones territoriales y funcionales y entre los senadores las organizaciones de derechos humanos.

\section{Semejanzas y diferencias políticas: elite parlamentaria y sociedad civil organizada}

El universo de la elite política chilena en los veinte años considerados resulta abultadamente sesgado hacia la Concertación, puesto que esta detentó el gobierno durante todo el período. Sin embargo, la encuesta registra también las características de la elite parlamentaria, lo que permite comparar las tendencias organizacionales entre los dos bloques políticos principales. 


\section{Tabla $\mathbf{N}^{\circ} 7$ \\ Parlamentarios pertenecientes a la Elite}

\begin{tabular}{|l|c|c|c|c|c|}
\hline & \multicolumn{2}{|c|}{ Derecha } & \multicolumn{2}{c|}{ Concertación } & TOTAL \\
\hline & Senadores & Diputados & Senadores & Diputados & \\
\hline Hombres & 11 & 40 & 14 & 68 & $\mathbf{1 3 3}$ \\
\hline Mujeres & 0 & 4 & 0 & 8 & 12 \\
\hline Sub Total & 11 & 44 & 14 & 76 & 145 \\
\hline TOTAL & \multicolumn{2}{|c|}{$\mathbf{5 5}$} & \multicolumn{2}{c|}{$\mathbf{9 0}$} & \\
\hline
\end{tabular}

Fuente: Encuesta Elite Política 2011

En el caso de la derecha se trata de 55 personas que han detentado cargos parlamentarios por más de un período. Entre ellas hay sólo 4 mujeres manifestando así una tasa de masculinidad aún más acentuada que sus pares de la Concertación, así como respecto del total de la elite (7,3\%). En cuanto a la pertenencia organizacional el panorama de la derecha se indica en la Tabla $\mathrm{N}^{\circ} 8$.

\section{Tabla $\mathbf{N}^{\circ} 8$ \\ Pertenencia organizacional según tipo de organización}

\begin{tabular}{|l|c|c|}
\hline \multicolumn{1}{|c|}{ Organización } & $\mathbf{\%}$ & $\mathbf{N}$ \\
\hline Organizaciones estudiantiles & 52,7 & 29 \\
\hline Colegios profesionales & 40,0 & 22 \\
\hline Org. Territoriales, vecinales o funcionales & 27,3 & 15 \\
\hline Organizaciones de voluntariado & 25,5 & 14 \\
\hline Asociaciones gremiales o empresariales & 18,2 & 10 \\
\hline Asociaciones y movimientos religiosos, & 18,2 & 10 \\
filosóficos o espirituales & & \\
\hline Clubes de membresia de pago & 16,4 & 9 \\
\hline Centros de estudios & 16,4 & 9 \\
\hline ONG & 9,1 & 5 \\
\hline Asociaciones y movimientos culturales & 5,5 & 3 \\
\hline Organizaciones sindicales & 3,6 & 2 \\
\hline Otra & 3,6 & 2 \\
\hline Asociaciones de Derechos Humanos & 1,8 & 1 \\
\hline Asoc. étnicas o comunidades indigenas & 0 & 0 \\
\hline
\end{tabular}

Fuente: Encuesta Elite Política 2011

Las dos prevalencias principales coinciden con el universo completo: en primer término los movimientos estudiantiles universitarios y en segundo término los colegios profesionales. Tal como en el caso anterior la universidad es ámbito de reproducción del liderazgo político, por lo que 24 
de 29 ocuparon cargos directivos. Mientras en los Colegios Profesionales no ocurre lo mismo, pues solo 3 de los 22 integrantes fueron dirigentes en ellos.

Pero le siguen en importancia no los centros de estudio, sino las organizaciones territoriales y las de voluntariado, seguidas por las religiosas y las asociaciones gremiales. Las primeras y las últimas pueden ser consideradas como lugares para reproducir el liderazgo, mientras entre las de voluntariado y las religiosas el fenómeno es más acotado (sólo la mitad de los parlamentarios miembros ejercieron liderazgo en ellas). Por último cabe destacar la importancia de los clubes de membresía (y por lo tanto pagados), que equiparan a los centros de estudio, indicando una tendencia de carácter socialmente más elitaria. Como era esperable, resulta mucho menor la proveniencia de las ONG y prácticamente nula la participación en agrupaciones de derechos humanos y sindicatos.

Una comparación con el resto de los parlamentarios muy mayoritariamente de la Concertación- en el mismo período, arroja el siguiente resultado, que se muestra en la Tabla $\mathrm{N}^{\circ}$ 9. Los parlamentarios de la Concertación provienen -aún más marcadamente que sus colegas de la Alianza- de los movimientos estudiantiles y colegios profesionales. También los concertacionistas tienen mayor peso de sus miembros provenientes de organizaciones territoriales y movimientos religiosos. Mucho más marcada todavía es la diferencia respecto de las asociaciones de derechos humanos, los centros de estudio y las ONG, lo cual le da el sello específico a esa bancada. Se trata de lugares no tradicionales de reproducción del liderazgo. A su vez son relativamente menos los de clubes de membresía (diferencia leve), organizaciones de voluntariado y asociaciones gremiales. Inversamente la derecha proviene menos del sindicalismo, aunque el porcentaje en el resto de los parlamentarios también es bastante bajo.

Tabla $\mathbf{N}^{\circ} 9$

Pertenencia organizacional según tipo de organización.

\begin{tabular}{|l|c|c|}
\hline \multicolumn{1}{|c|}{ Organización } & $\%$ & N \\
\hline Organizaciones estudiantiles & 54,4 & 49 \\
\hline Colegios profesionales & 45,6 & 41 \\
\hline Centros de estudios & 27,8 & 25 \\
\hline Asociaciones y movimientos religiosos, & 32,2 & \\
filosóficos o espirituales & & 29 \\
\hline ONG & 22,2 & 20 \\
\hline Org. Territoriales, vecinales o funcionales & 33,3 & 30 \\
\hline Asociaciones de Derechos Humanos & 28,9 & 26 \\
\hline Clubes de membresía de pago & 15,6 & 14 \\
\hline Organizaciones de voluntariado & 17,8 & 16 \\
\hline Asociaciones gremiales o empresariales & 14,4 & 13 \\
\hline Organizaciones sindicales & 8,9 & 8 \\
\hline Asoc. étnicas o comunidades indigenas & 1,1 & 1 \\
\hline
\end{tabular}

Fuente: Encuesta Elite Política 2011 
Tabla $\mathrm{N}^{\circ} 10$

Perfil de las bancadas parlamentarias según principales organizaciones de proveniencia

\begin{tabular}{|c|c|}
\hline Derecha & Concertación y otros \\
\hline \multicolumn{2}{|c|}{ (53\%) Movimiento Estudiantil Universitario (54\%) } \\
\hline \multicolumn{2}{|c|}{$(40 \%)$ Colegios Profesionales (46\%) } \\
\hline \multicolumn{2}{|c|}{ (27\%) Orgs. Territoriales y Funcionales (33\%) } \\
\hline Orgs. de Voluntariado (26\%) & Asoc. y Movs. Religiosos y filosóficos (32\%) \\
\hline Asoc. y Movs. Religiosos y filosóficos (18\%) & Asoc. de Derechos Humanos (29\%) \\
\hline Asoc. Gremiales y Empresariales (18\%) & Centros de Estudios (28\%) \\
\hline
\end{tabular}

Fuente: Encuesta Elite Política 2011

Se puede concluir entonces que el perfil comparado de los parlamentarios indica una mayor vinculación de la bancada oficialista a las organizaciones de la sociedad civil en la mayor parte de las categorías, con un reclutamiento que combina fuentes tradicionales con no tradicionales. La derecha presenta menor pertenencia organizacional previa, pero comparte las principales organizaciones de proveniencia y cuenta con importantes sectores provenientes del ámbito del voluntariado, las organizaciones religiosas y empresariales.

Con respecto al conjunto de la elite, la mayor diferencia que ofrece el segmento parlamentario es su proveniencia mayoritaria del movimiento estudiantil, la mayor importancia relativa de las organizaciones territoriales en su composición y la mayor vinculación con asociaciones de derechos humanos y movimientos religiosos o filosóficos en el caso de la Concertación y con los gremios y el voluntariado en el caso de la derecha. ${ }^{23}$

\section{Conclusiones}

El artículo ha analizado la composición de la elite política chilena entre 1990 y 2010 a la luz de tres aspectos: su participación previa en organizaciones de la sociedad civil, su composición interna de acuerdo a segmentos de la elite y sus diferencias entre bloques políticos en el parlamento. La encuesta aplicada a 386 personas que han ocupado posiciones político-institucionales de elite en el período ha permitido establecer la prevalencia abrumadora del sexo masculino y del patrón social de clases medias profesionales en todas las categorías (ejecutivo, parlamento y partidos). Mayoritariamente esta elite tuvo participación en organizaciones de la sociedad civil antes de ocupar sus cargos.

La importancia de los factores bajo estudio radica en el hecho que una elite proveniente muy mayoritariamente de la sociedad civil organizada, es reclutada selectivamente según pautas del proceso político que indi- 
can importantes cambios en las relaciones entre la sociedad y la política.

La composición de la elite gobernante se refleja en las organizaciones de la sociedad civil en los cuales participaron previamente, las cuales han sido medios de reproducción de su liderazgo, aún en condiciones de interdicción política, como fue el período dictatorial. El grupo mayoritario lo hizo en organizaciones que tradicionalmente han cumplido esa función para los grupos medios: los movimientos estudiantiles y los colegios profesionales. Sin embargo sólo en el parlamento son mayoría los provenientes del movimiento estudiantil universitario.

Un segundo grupo importante, sin embargo, ofrece un perfil más tecnopolítico y muestra una modificación de los patrones de reclutamiento y reproducción del liderazgo. Es el caso de los Centros de Estudio y, secundariamente, de los directivos de las ONG. El primero de ellos pareciera ser un grupo de creciente importancia y proyección futura, mientras el segundo una situación más propia de una coyuntura donde la sociedad civil fue un espacio sustitutivo de la acción política propiamente tal y un espacio para sus líderes. Los Centros de Estudio, sin embargo, se relacionan estrechamente con determinadas opciones y partidos políticos, pues no se trata de centros pluralistas o netamente académicos y el reclutamiento se concentra en un pequeño número de ellos.

El impacto de la tecnopolítica es menor en los parlamentarios que no accedieron a la conducción superior del ejecutivo. También es mayor su vinculación a organizaciones tradicionales de reproducción del liderazgo de diferentes sectores medios profesionales y empresariales, así como su pertenencia a organizaciones religiosas.

Nuestras conclusiones avalan la idea de que las condiciones del elitismo democrático reforzado favorecieron el surgimiento de una elite política relativamente homogénea en términos sociales, especialmente educacionales. Pero también permiten relevar la importancia de la socialización política a través de la participación en un número relativamente restringido de organizaciones e instituciones, que tienden a concentrar a los miembros de la elite. Es el caso de los colegios profesionales, los centros de pensamiento y de las ONG, donde solo unas pocas instituciones concentran a gran parte de los entrevistados. Pero también lo es en el movimiento estudiantil. Si se cruza la participación estudiantil con las universidades de proveniencia, se verifica la concentración abrumadora de los integrantes de la elite en la Universidad de Chile y la Universidad Católica, las principales universidades, ambas ubicadas en la capital del país.

Las relaciones entre la sociedad civil organizada y el poder político se han transformado significativamente. Se cierra el acceso de los sectores populares organizados, quienes quedan fuera de las posiciones de poder institucionalizadas, las cuales habían logrado penetrar en alguna medida en el período anterior a 1973. Las mujeres, por su parte, logran aún una exigua presencia en la elite política. Por otra parte se incrementa el peso de los 
estamentos de mayor educación y alta tecnificación, vinculados a los partidos políticos, pero con importantes márgenes de independencia. En el caso del ejecutivo, la pertenencia a centros de estudio desplaza al movimiento estudiantil como ámbito de reclutamiento de líderes políticos. Así, se configura una trayectoria de baja movilidad social: si bien la elite política proviene de la sociedad civil, en la práctica lo hace desde la elite de esa sociedad civil y se aleja de ella en su desarrollo. Las consecuencias a largo plazo de ello para la democracia y el distanciamiento entre la política y la ciudadanía deberán ser analizadas en estudios posteriores. 


\section{Notas}

${ }^{1}$ El intento de formar un tercer partido de derecha por parte del senador Francisco Javier Errázuriz no fructificó.

${ }^{2}$ En el Senado en casi veinticinco años- sólo un parlamentario ha logrado, en 2006 y 2013, ser electo por fuera de los dos pactos vigentes desde 1989.

${ }^{3}$ Ver la secuencia de Encuestas semestrales del Centro de Estudios Públicos (CEP) (http:// www.cepchile.cl/dms/lang_1/doc_4936.html ) y mensuales de Adimark (http:// www.adimark.cl/es/estudios/documentos/003_ev_gob_3_mar12.pdf: láminas 51 y ss.).

${ }^{4}$ En la Democracia Cristiana (DC) el senador y ex presidente del partido, Adolfo Zaldívar, formó un nuevo partido y se alió con la derecha desde 2009. Otros dirigentes, principalmente socialistas, renunciaron a su partido para ser candidatos presidenciales en 2009, como el ex ministro Jorge Arrate, el senador Alejandro Navarro y el ex diputado Marco Enríquez-Ominami. Este último obtuvo un 20\% de los votos en 2009 y formó el Partido Progresista (PRO), postulando nuevamente a la presidencia en 2013 (obteniendo el 11\%). Todos ellos han conformado nuevas agrupaciones políticas que hasta la legislatura 2010 2014 no habían logrado acceso al parlamento por la vía electoral.

${ }^{5}$ Aún no ha sido suficientemente estudiado el enorme impacto de la interpretación del libro de Arturo Valenzuela, tanto en Chile como en la ciencia política internacional ocupada de los asuntos de la democracia en los años setenta y ochenta. En cualquier caso la actualidad política del texto para el diseño de la transición chilena era algo explícito para quienes publicaron su traducción en 1989 a través de FLACSO en Chile. Ver al respecto las palabras introductorias de Angel Flisfich y Juan Linz a la traducción de 1989. Curiosamente, sin embargo, la principal recomendación política del autor, establecer un régimen parlamentario, no fue tomada en consideración durante la transición chilena.

${ }^{6}$ En Chile se denomina Chicago Boys a los discípulos de Milton Friedmann, formados mayoritariamente en la Universidad de Chicago y que controlaron la política económica durante la mayor parte de la dictadura militar. CIEPLAN -Corporación de Investigaciones Económicas para Latinoamérica- es un centro de estudios de gran influencia política. Creado en los años setenta, albergó a los economistas democratacristianos expulsados de la Universidad Católica y tuvo gran influencia en los gobiernos de la Concertación. Expansiva fue un think tank creado en los años noventa como una red de profesionales destinado a influir en políticas públicas con un enfoque liberal. Tuvo una importante presencia en los primeros gabinetes del gobierno Bachelet (2006 - 2010).

${ }^{7}$ En los hechos se cumplió la previsión planteada por Silva respecto de los partidos políticos, quien señaló: No espero una restauración del su antigua posición pivotal en el sistema político chileno. Pueden encontrar quizás un reaseguro (redoubt) en el Congreso, pero no en una posición dominante a nivel ministerial, como fue el caso antes de septiembre de 1973 (Silva 1991: 407).

${ }^{8}$ El segmento ejecutivo está compuesto por tres grupos: a) Presidentes de la república, ministros y subsecretarios; b) intendentes regionales, jefes de división y de gabinete que permanecieron más de un período presidencial en el cargo; c) consejeros del Banco Central; superintendentes, presidentes del Consejo Nacional de Televisión; vicepresidentes de CORFO; Directores de Presupuesto y Directores Nacionales de algunos servicios de espe- 
cial relevancia en el poder ejecutivo.

${ }^{9}$ Naturalmente el universo seleccionado no incluye posiciones de elite política no institucionales, como ocurre con asesores externos y otras personas. En trabajos anteriores utilizamos también el enfoque de redes de política pública para comprender el alcance y características de formas menos institucionalizadas de ejercicio del poder (Delamaza 2010; Delamaza et al. 2012).

${ }^{10}$ Para efectos operacionales se determinó la pertenencia de cada encuestado a una sola categoría dentro de la elite. Para ello se estableció una jerarquía de posiciones consideradas según su mayor poder relativo. Ello nos permitió clasificar a los encuestados según la posición de mayor poder alcanzada, sin considerar otras posiciones que también puede haber ocupado. El orden establecido fue: presidente y ministros; senadores; diputados; subsecretarios e intendentes por más de un período presidencial; ejecutivos de entidades semiautónomas; jefes de división y gabinete por más de un período presidencial y directivos de partidos políticos por más de un período. Esta clasificación produjo una subrepresentación de los directivos de partidos políticos, puesto que la gran mayoría de ellos ocupó también alguna de las otras posiciones, consideradas de mayor poder.

${ }^{11}$ Dicha superposición no implica que todos los integrantes, ni los dirigentes de las organizaciones de la sociedad civil fuesen militantes. Solo significa que el segmento de pertenecientes a dichas organizaciones y movimiento que transitó hacia la elite política eran muy mayoritariamente militantes políticos. No abordamos en este artículo la relación entre pertenencia organizacional y militancia con anterioridad al ingreso a la elite.

${ }^{12}$ Ninguno de ellos, sin embargo, continuó en la carrera política. Otros dirigentes sindicales, como el socialista Arturo Martínez, que fue presidente de la Central Unitaria de Trabajadores, y el comunista Cristián Cuevas, dirigente de los trabajadores del cobre, han intentado llegar al parlamento sin éxito.

${ }^{13}$ Es posible que eso haya variado en el período posterior a 2010. Por primera vez en muchos años se eligió como presidente a un acaudalado empresario (Sebastián Piñera) y gran parte de su primer gabinete y equipos técnicos fue reclutado entre cuadros de ejecutivos privados y empresariales.

${ }^{14}$ En este trabajo no abordaremos las organizaciones territoriales y funcionales, centrándonos en los cuadros de la elite provenientes de las clases medias.

${ }^{15}$ Sobre la historia de la FECH, ver Brodsky (1988), García (2006). Sobre el paso de la dirigencia estudiantil a la arena política en diferentes momentos históricos, ver Gazmuri (2001) y Huneeus (2000). Sobre el caso del Movimiento Gremial y la derecha, ver Valdivia (2010).

${ }^{16}$ Por cierto hay dirigentes profesionales en el parlamento, pero no es la pauta predominante de transición de liderazgo.

${ }^{17} \mathrm{El}$ 58,5\% de los encuestados declara profesar la religión católica, mientras el 29,7\% señala no profesar religión alguna. La influencia de la Iglesia Católica incluye por cierto a la DC, pero también a una buena parte de la izquierda renovada actual, escindida de la DC a fines de los años sesenta. En la derecha, la UDI, el partido heredero de Pinochet, es también un partido ligado a movimientos conservadores católicos. 
Polis, Revista Latinoamericana, Volumen 12, $N^{\circ}$ 36, 2013

${ }^{18}$ Destacan las instituciones respaldadas por los jesuitas, como el Centro Bellarmino, ILADES y DESAL, fundada por el jesuita belga Roger Vekemanns, quien también fundó la Escuela de Sociología de la Universidad Católica (Beigel 2011).

${ }^{19} \mathrm{La}$ importancia académica de estos centros se puede apreciar si se considera que entre 1980 y 1985 FLACSO reporta 157 presentaciones en seminarios extranjeros y 183 en Chile, mientras CIEPLAN 139 en el extranjero y 204 en Chile (Lladser 1990: 256).

${ }^{22}$ Durante los años ochenta surgieron también otros centros de pensamiento ligados a corrientes ideológicas o políticas como el Centro de Estudios Públicos (CEP) ligado a la derecha liberal, el Centro de Estudios del Desarrollo (CED) a la DC, VECTOR al PS y el Instituto Científico Alejandro Lipschutz (ICAL) al PC.

${ }^{21}$ El ciclo no se detendrá, pues posteriormente surgen otros think tanks ligados a políticos, partidos y corrientes, así como fundaciones de los ex presidentes de la república: Expansiva (fundada por Andrés Velasco, luego ministro de Hacienda y precandidato presidencial), Corporación Justicia y Democracia (Patricio Aylwin), Fundación ProyectAmerica (ex ministro José Antonio Viera Gallo); Fundación Democracia y Desarrollo (Ricardo Lagos), Progresa (Marco Enríquez-Ominami), Dialoga (Michelle Bachelet), entre otros.

${ }^{22}$ Llama la atención que los dos primeros sean centros pertenecientes a la AHC, que ofrecen un perfil mixto entre centro de estudio y ONG (algo similar sucede con el CIDE).

${ }^{23}$ Estos datos coinciden con los resultados de un estudio sobre diputados entre 1961 y 2010. En él se establece que, por una parte se ha incrementado la participación previa de los diputados en el movimiento estudiantil (39\% en el periodo 19902010 contra 24\% en el período anterior a 1973) y, por otra, ha disminuido la presencia relativa de directivos de la sociedad civil (54\% antes de 1973 contra 48\% después de 1990, con tendencia a la baja durante período) (Cordero y Funk 2011: 63). 


\section{Bibliografía}

Alcántara, M. (2012), El oficio de político. Tecnos, Madrid.

Avritzer, L. (2002), Democracy and the public space in Latin America. Princeton University Press.

Beigel, F. (2011), Misión Santiago. El mundo académico jesuita y los inicios de la cooperación internacional católica. Lom ediciones, Santiago de Chile.

Berkowitz, S. (1982), An introduction to structural analysis. The network approach to social research, Butterworths, Toronto.

Best, H. (2011), “The Elite-Population Gap in the Formation of Political Identities. A Cross-Cultural Investigation”. Europe-Asia Studies, 63(6), 9951009. doi: 10.1080/09668136.2011.585751

Best, H. y M. Cotta (2000), Parliamentary representatives in Europe 18482000. Legislative recruitment and careers in eleven European countries. Oxford University Press, Oxford.

Bourdieu, P. (1997), Capital cultural, escuela y espacio social. Siglo XXI Editores, México D.F.

Ídem (2013), La nobleza de Estado: Educación de elite y espíritu de cuerpo. Siglo XXI Editores, Buenos Aires.

Brodsky, R. (1988), Conversaciones con la FECH. CESOC, Santiago.

Brunner, J. y A. Barrios (1987), Inquisición, mercado y filantropía. Ciencias sociales y autoritarismo en Argentina, Brasil, Chile y Uruguay. FLACSO, Santiago.

Centeno, M. y P. Silva (eds.) (1998), The politics of expertise in Latin America. Mc Millan Press.

Collier, R. y D. Collier (2002), Shaping the political arena. Critical junctures, the labor movement and regime dynamics in Latin America. University of Notre Dame Press.

Collier, R. y S. Handlin (2010), Reorganizing Popular Politics. Participation and the new interest regime in Latin America. The Pennsilvania State University Press.

Cordero, R. y R. Funk (2011), “La política como profesión. Cambio partidario y transformación social de la elite política en Chile 1961 - 2010”. Política y Gobierno Vol. XVIII, Núm. 1, pp. 3971.

Correa, S. (2004), Con las riendas del poder. La derecha chilena en el 
siglo $X X$. Sudamericana, Santiago de Chile.

Cortés, A. (2000), El circuito extrainstitucional del poder. ChileAmérica / CESOC, Santiago.

Dogan, M. (1999), "Les professions propices à la carrière politique. Osmoses, filières et viviers.” En Michel Offerlé (Ed.), La profession politique XIXe-XXE siècles. Belín, Paris.

Delamaza, G. (2010), Construcción Democrática, participación ciudadana y políticas públicas en Chile. https://openaccess.leidenuniv.nl/handle/ 1887/15360 Leiden University, Leiden.

Ídem (2011), “Elitismo democrático, líderes civiles y tecnopolítica en la reconfiguración de las elites políticas”.En: P. Güell y A. Joignant: Notables, tecnócratas y mandarines. Elementos de sociología de las elites en Chile (1990-2010). Ediciones de la Universidad Diego Portales, Santiago.

Ídem et al. (2012), "Redes de política pública y agendas de participación ciudadana en el Chile post- transicional: ¿Desafiando la política o recreando sus límites?”, Revista Gestión y Política Pública, Vol XXI, N 1, México D.F., pp. 4586

Domínguez, J. (ed.) (1997), Technopols. Freeing politics and markets in Latin America in the 1990s. University Park: Pennsylvania State University Press.

Espinoza, V. (2010), “Redes de poder y sociabilidad en la élite política chilena. Los parlamentarios 1990-2005”. En: POLIS, Volumen 9, No 26, 2010, p. 251-286.

Garretón, M. (1985), La problemática de la transición a la democracia en Chile: Una síntesis. Washington D.C.

Gárate, M. “Think Tanks y Centros de Estudio. Los nuevos mecanismos de influencia política en el Chile post-autoritario”, Nuevo Mundo Mundos Nuevos [En línea], Coloquios, Puesto en línea el 14 enero 2008, URL : http://nuevomundo.revues.org/11152 ; DOI : 10.4000/nuevomundo.11152

García, D. et al. (2006), Los muchachos de antes. Historias de la FECH 1973 - 1988. Universidad Alberto Hurtado, Santiago.

Gazmuri, C. (2001), Notas sobre las elites chilenas (1930 - 1999). Documento de Trabajo $\mathrm{N}^{\circ} 3$, Santiago.

González Bustamante, B. (2013), "Factores de acceso y permanencia de la élite política gubernamental en Chile (1990-2010)”. Política, Revista de Ciencia Política, 51(1), 119-153.

Higley, J. y M. Burton (1989), “The Elite Variable in Democratic Transitions 
and Breakdowns”. American Sociological Review, 54(1), 17-32. doi: $10.2307 / 2095659$

Higley, J. y R. Gunther (1992), Elites and Democratic Consolidation in Latin America and Southern Europe. Cambridge University Press, Cambridge.

Huneeus, C. (2000), El régimen de Pinochet. Sudamericana, Santiago.

Ibáñez, A. (2003), Herido en el ala. Estado oligarquías y subdesarrollo. Chile 19241960. Universidad Andrés Bello, Santiago.

Joignant, A. (2009), El estudio de las elites: un estado del arte. UDP, Serie Documentos de Trabajo $\mathrm{N}^{\circ} 1$, Santiago.

Liphart, A. (1999), Las democracias contemporáneas: un estudio comparativo. Ariel, Barcelona.

Lladser, M. (1986), Centros privados de investigación en ciencias sociales en Chile. AHC / FLACSO, Santiago.

Lladser, M. (1990), La investigación en ciencias sociales en Chile: su desarrollo en los centros privados, 1973 - 1988. En: J. Abalos et al. Una puerta que se abre. Los organismos no gubernamentales en la cooperación al desarrollo. Taller de Cooperación al Desarrollo, Santiago.

Marenco, A. y M. Serna (2007), "Por que carreiras políticas na esquerda e na direita $\mathrm{n} \sim$ ao $\mathrm{s}$ ao iguais? Recutamento legislativo em Brasil, Chile e Uruguai”. Revista Brasileira de Ciências Sociais, 22(64), 93-113. doi: 10.1590/S0102-69092007000200008

Martucelli, D. y M. Svampa (1993), “La doble legitimidad del populismo”. Proposiciones $\mathrm{N}^{\circ}$ 22, pp. 226238.

Montecinos, V. (1998), Economists, politics and the State: Chile 19581994. CEDLA, Amsterdam.

Moulian, T. (2006), Fracturas. De Pedro Aguirre Cerda a Salvador Allende (19381973). Lom Ediciones, Santiago.

Norris, P. (1997), Passages to Power: Legislative Recruitment in Advanced Democracies. Cambridge University Press, Cambridge.

Nun, J. (2002), La democracia. ¿Gobierno del pueblo o gobierno de los políticos? Fondo de Cultura Económica, México.

Offerlé, M. (2004), Los partidos políticos. LOM Ediciones, Santiago de Chile.

Otano, R. (1995), Crónica de la transición. Planeta, Santiago. 
Pakulski, J. (2012), “Introduction: John Higleys Work on Elite Foundations of Social Theory and Politics”. Historical Social Research-Historische Sozialfourschung, 37(1), 9-20.

Piñeiro, R. (2009), “La selección de candidatos en América Latina”. Revista de Ciencia Política, 29(1), 201-203.

Putnam, R. (1976), The Comparative Study of Political Elites. Prentice Hall, Englewood Cliffs, N.J.

Ruiz, C. (1993), Seis ensayos sobre teoría de la democracia. Universidad Nacional Andrés Bello, Santiago.

Salazar, G. y J. Pinto (1999), Historia Contemporánea de Chile Tomo I. Lom Ediciones, Santiago.

Schumpeter, J. (1946), Capitalism, socialism, democracy. Harper, New York.

Serna, M. (2006), “Las vías hacia el poder político. Bases sociales y carreras parlamentarias”. En Enrique Mazzei (Ed.), El Uruguay desde la Sociología IV. Departamento de Sociología, Facultad de Ciencia Sociales, Universidad de la República, Montevideo.

Siavelis, P. y S. Morgenstern (2008), Pathways to Power: Political Recruitment and Candidate Selection in Latin America. University Park, PA: The Pennsylvania State University Press.

Silva, P. (1991) "Technocrats and politics in Chile: From the Chicago Boys to the CIEPLAN monks”. Journal of Latin American Studies 23(2), pp. 385410 .

Ídem (2011), “La elite tecnocrática en la era de la Concertación”. En: A. Joignant y P. Güell: Notables, tecnócratas y mandarines. Elementos de sociología de las elites en Chile (1990 2010). Ediciones Universidad Diego Portales, Santiago.

Valdés, J. (1995), Pinochets economists: the Chicago school of economics in Chile. Cambridge University Press, Cambridge.

Valdivia, V. (2010), Nacionales y gremialistas. El parto de la nueva derecha política chilena. 1964 - 1973. Lom Ediciones, Santiago.

Valenzuela, A. (1978), The breakdown of democratic regimes. Chile. The Johns Hopkins University Press, Baltimore. 